nished; shrill tubular note. Dr. Fish pronounced the pain to be pleuritic. Linseed-meal poultices were applied over the back and side, the nutrient enemata were discontinued, and the patient was ordered brandy and milk. Temperature $103^{\circ}$; pulse $120 .-10$ P.M.: Temperature $100^{\circ}$; pulse 120 . 4th. - 9 A.M.: Temperature $100 \cdot 2^{\circ}$; pulse 99. Delirious part of the night, but obtained some sleep in the early morning. Free from pain. Bowels open.

5th. $\rightarrow 9$ A.M.: Temperature $99 \cdot 2^{\circ}$; pulse 132 . No vomiting. Respiration more hurried. Takes ten ounces of brandy. 6th.-Slept well. Decided improvement. Tongue clean. Bowels open ; motions solid. Temperature $99^{\circ} 2^{\circ}$. -8 P.M.: Temperature $100^{\circ}$.

7th.-Physical signs much the same. Takes nourishment freely. Temperature $99 \cdot 2^{\circ}$. -8 P.M.: Temperature $100.8^{\circ}$.

8th.-Temperature $994^{\circ}$; less dulness on percussion ; less pain.-8 P.M.: Temperature $100^{\circ}$.

9th.-Temperature $99^{\circ}$; face pinched and dusky; breathing hurried; respiration 26 ; suffers but little pain.-8 P.M. Temperature $998^{\circ}$.

10th. - Temperature $99 \cdot 2^{\circ}$; restless and delirious in the night; takes but little nourishment. -8 P.M.: Temperature $99^{\circ}$; more pain in side ; bulging in intercostal spaces more dulness on percussion; had severe paroxysms of dyspnoea at night.

11th. - Had a restless night; great pain in side; more bulging in intercostal spaces; area of dulness greater. About 8.30 A.M. the patient asked to be raised in bed, when he suddenly fell back asphyxiated.

Necropsy, Feb. 13th, 10 A.M.-Chest: Left pleural cavity eontained upwards of a quart of muco-purulent fluid; left lung compressed and flattened, weighed only seven ounces and a half; pieces of it sank in water. Right lung weighed twenty-two ounces and a half, and contained a few tubercles, -Heart healthy.-Abdomen: Spleen and liver healthy; left kidney seven ounces, right one six ounces; they were both examined microscopically by Mr. Augustus Pepper, who pronounced them healthy. The bladder and prostate were healthy; there were two false passages extending into the substance of the gland for a short way, which were lined with a mucous membrane, and were evidently of considerable age. In the urethra the remains of the stricture could be seen, and it was evident that the stone, which was phosphatic, had been tormed in the dilated portion of the canal behind the contraction.

Remarks by Mr. TEEVAN. - The patient when quite cured of his local ailment, and about to return home cured, was attacked by pleurisy. Unfortunately the man's constitution had been deteriorated by the fever and ague from which he had suffered whilst in the tropics, so that he was predisposed to catch cold, and formed one of the many victims to the excessively low temperature which prevailed at the time of his illness. Happily, in the present instance, no operation had been performed, so that surgery must be held blameless for the unfortunate termination. When the patient was admitted he was not suffering from retention, and was able to pass urine by the side of the calculus. The case illustrated what could be achieved by apparently so insignificant an instrument as a fine whalebone bougie, which in the present instance had effected the dilatation of the stricture and the expulsion of the stone.

\section{SOMERSET HOSPITAL, CAPE TOWN, CAPE OF GOOD HOPE.}

INGUINAL ANEURISM ; LIGATURE OF THE RIGHT COMMON ILIAC ARTERY; RECOVERY.

(Under the care of Dr. A. L. Chrappini.)

THE following notes were taken by the late Dr. W. $H$. Wood :-

W. H_- aged forty, was admitted on January 2nd, suffering from a very large inguinal aneurism, which could be distinctly seen pulsating through his trousers, and forming a prominence on the right side. He was of intemperate habits, but had never had syphilis. He stated that about fifteen months before admission he was engaged loading a vessel with copper ore at night, and that when lifting a particularly heavy bag he felt something give way on his right side, and he immediately had very severe pain in the right groin, and about three hours after this, on putting his hand within his trousers-pocket, he felt a lump, which was not very hard, and about the size of a pigeon's egg. At nine next morning he showed it to a medical man, who ordered him to poultice the swelling, which was now very hard. He lay up and poulticed for nearly a week, when, the pain having diminished, he returned to work, and two months after again showed it to the same gentleman. The tumour was now the size of a hen's egg, and the man noticed for the first time that it pulsated. He was told to continue the poultices. Time passed on, the man being at work on and off; the tumour still increasing and causing great pain down the right leg. Abont three months before admission "the "lump" was, he said, about the size of a "baby's head," and he again showed it to the doctor, who advised him to poultice continually. A few weeks before admission he saw another medical man, who immediately ordered him to the hospital, to which he went by sea.

On examination, an immense pyramidal tumour was seen, pulsating with a strong expanding impulse, occupying the whole of the right iliac region, being raised about five inches above the surface; a tape laid across it measuring just a fraction under twelve inches from edge to edge. The upper limit was level with the crest of the ilium; to the left it approached closely to the pubes, while it was prolonged downwards into the thigh, Poupart's ligament being tightly stretched over its lower portion. The tumour was soft and elastic; at the apex the sac was very thin, and the skin a dusky purple, and it was evident it must soon give way. The right leg was considerably swollen; the temperature was the same in both legs.

On the 8th, or six days after admission, the patch at the apex was larger and thinner, and after consultation it was decided to operate the next day.

On the 9th Dr. A. L. Chiappini, the visiting surgeon, accordingly proceeded to operate, making a semilunar (from the small space at his disposal, almost a semicircular) incision, with its convexity at the furthest about five inches from the umbilicus. The peritoneum, which was not adherent, was pushed back with the intestines, and the common iliac artery exposed (as was expected, there was nothing to be seen of the external iliac artery) and ligatured with thick silk. One end of the ligature was left hanging out, and carbolic dressings were applied to the wound, which was brought together by a few sutures. He was then put to bed, and the leg, previously shrouded in cotton wool, was surrounded with hot sand bags and hot-water bottles. In the evening his pulse was 90 ; he had not much pain anywhere. Had half a grain of morphia. Had had a good night and passed water freely. Next morning the tongue was clean pulse 112 ; temperature of body $995^{\circ}$. At 9 P.M. the pulse was 100 ; temperatare $99^{\circ}$. Repeat the sedative draught.

He continued without one bad symptom, not suffering so much from pain and numbness in the leg as before the operation, and having perfect sensation in the leg. The tumour very rapidly decreased, at one time, however, threatening to suppurate, and on the 29 th day after the operation the liga. ture came away. The man is now in perfect health, and working as a navvy on the railway works.

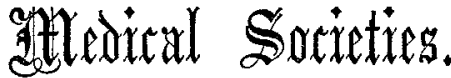

\section{ROYAL MEDICAL \& CHIRURGICAL SOCIETY.}

\section{Cholecystotomy for Dropsy of Gall-bladder due to the Im-} paction of Gall-stone.-Gastrotomy in Extra-uterine Pregnancy.

THE ordinary meeting of this Society was held on the 11th inst.; Mr. Erichsen, F.R.S., President, in the chair. Two papers, by Mr. Lawson Tait, were read, both dealing with abdominal surgery, and interesting not only for their intrinsic importance, but for the discussion raised on the side issue of the value of antiseptic measures in peritoneal operations, Mr. Spencer Wells, Mr. K. Thornton, Mr. Holmes, and others joining in the debate.

Mr. GAY exhibited the specimen of Cancer of the Rectum, removed by excision of three inches of the gut, upon which he had read a paper last session. The patient had since died from extension of the disease to the uterus. He also showed a similar specimen, forwarded by Mr. Lowson, of Hudders- 